\title{
Ultrasonic Evaluation of Mechanical Properties of Thick, Multilayered, Filament Wound Composites
}

Harold E. Kautz

Lewis Research Center

Cleveland, Ohio

September 1985

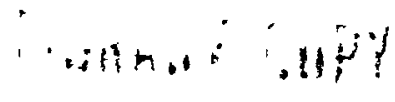

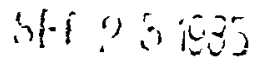

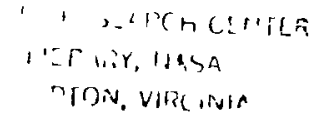




\title{
ULTRASONIC EVALUATION OF MECHANICAL PROPERTIES OF THICK,
}

MULTILAYERED, FILAMENT WOUND COMPOSITES

\author{
Harold E. Kautz \\ National Aeronautics and Space Administration \\ Lewis Research Center \\ Cleveland, Ohio 44135
}

\begin{abstract}
SUMMARY
A preliminary investigation was conducted to define capabilities and limitations of ultrasonic and acousto-ultrasonic measurements related to mechanical properties of filament wound graphite/epoxy composite structures. The structures studied were segments of filament wound cylinders formed of multiple layers of hoop and helical windings. The segments consisted of from 24 to 35 layers and ranged from 3.02 to $3.34 \mathrm{~cm}$ in wall thickness. The resultant structures were anfsotropic, heterogeneous, porous, and highly attenuating to ultrasonic frequencies greater than $1 \mathrm{MHz}$. The segments represent structures to be used for space shuttle booster cases. Ultrasonic velocity and acousto-ultrasonic stress wave factor measurement approaches are discussed. Correlations among velocity, density, and porosity, and between the acoustoultrasonic stress wave factor and interlaminar shear strength are presented.
\end{abstract}

\section{INTRODUCTION}

Multilayered, filament wound composite (FWC) structures are of interest for aerospace appiications such as rocket booster cases and aircraft fuselages. Reusable FWC booster cases are planned for future shuttle missions to reduce weight and increase payloads. Like other composite structures. FWC structures possess physical and mechanical properties that are created "in place", e.g., during fabrication and curing. These composites have unique structural properties that require new nondestructive evaluation (NDE) approaches. Development of these new materials requires parallel development of NDE methods to characterize inherent mechanical properties as well as defects. NDE techniques are needed for shuttle FWC booster cases to verify their initial condition and reusability after damage incurred during use.

Uitrasonic and acousto-ultrasonic methods are suitable for assessing mechanical properties such as elastic moduli, tensile and shear strengths, fatigue damage, and overall defect state in composite structures (refs. 1 to 13). Although ultrasonic methods are viable for thin composite laminates they are difficult to apply to thick, multilayered, and inherently porous FWC structures. FWC structures have high attenuation for ultrasonic waves at frequencies above $1 \mathrm{MHz}$. This is typical of composite laminates, but aggravated by the greater thickness and heterogeneity of FWC booster case materials. These factors combine to pose unique problems for measuring velocity and attenuation leading to characterization of mechanical property and defects.

This report describes an investigation of ultrasonic and acoustoultrasonic NDE methods that can be adapted for inspecting FWC structures in the form in which they will be fabricated and ultimately employed. The methods 
investigated have the potential of verifying mechanical properties and characterizing defect states. The approach employed is to first study the material apart from its ultimate hardware configuration. Accordingly, this report describes a study of samples of FWC material of the type being developed for space shuttle booster cases. Results of ultrasonic strategies for measuring material morphology and mechanical property variations are described. The emphasis is on ultrasonic velocity and acousto-ultrasonic measurement for assessing density, porosity, interlaminar shear strength, and related factors.

Mr. John Knadler of Marshall Space Flight Center provided the filament wound materials used in this study, and $\mathrm{Mr}$. James Kordig of Hercules provided the technical data on their fabrication.

\section{MATERIALS}

\section{Representative FWC Segments}

The materials were characterized using $x$-rays, through transmission ultrasonic C-scans, and a combined ultrasonic C-scan A-scan method. FWC segments were cut from cylinders fabricated as booster case test hardware. A full-scale space shuttle booster case cylinder is shown in figure 1. Two representative segments were selected for this study. Their salient characteristics are given in table I. Segment 1 was cut from a quarter-scale, full wal1-thickness cylinder that had an inside diameter of $76 \mathrm{~cm}$ and wall thickness of $3.01 \mathrm{~cm}$ (figs. 2(a) and (b)). Segment 2 (figs. 2(c) and (d)) was from a full scale, full wall-thickness cylinder with an inside diameter of $368 \mathrm{~cm}$ and wall thickness of $3.34 \mathrm{~cm}$.

Each segment consists of a Kevlar cloth substrate and layers of helical and hoop windings of graphite fiber in an epoxy matrix. The helical and hoop layers were wound with graphite fiber tows preimpregnated with the epoxy resin system HBRF 55A. The cloth was impregnated with the epoxy resin system $35015 A$.

Figures $3(a)$ and (b) are radiographs of segments 1 and 2 respectively. The radiographs show $x$-ray density variations in both segments. Low density regions appear to run along fiber winding directions. These low density regions are believed to be due primarily to the voids and porosity.

Ultrasonic through transmission $C$-scans of segments 1 and 2 appear in figures $4(a)$ and (b), respectively. Like the radiographs, the C-scans show considerable nonuniformity. There is a lack of any apparent correspondence between the $\mathrm{C}$-scans and radiographs. This is expected because ultrasonic transmission is strongly influenced by individual discontinuities and interfaces between layers while the radiographs show only the net variation in $x$-ray density.

The segments can be expected to be nonuniform through the thickness as well as laterally. Individual discontinuities and interfaces between layers can be observed in A-scans. This is illustrated in figure 5 . Figure 5(a) shows a photograph of the edge of a specimen cut from segment 2 . About $1 / 4$ of the thickness in from the left, or inside diameter, side is the exposed edge of a plane of high porosity. Along with this photograph are two A-scan time records, one obtained using a $0.5 \mathrm{MHz}$ center frequency transducer, and the 
other using a $1 \mathrm{MHz}$ transducer. The $0.5 \mathrm{MHz}$ A-scan exhibits backscatter signals from the left end and the right end of the specimen with ultrasonic signal approaching from the left. It also features a prominent backscatter from about 1/4 in from the left side. We assume to identify the plane of high porosity as the source of that backscatter. The $1 \mathrm{MHz}$ transducer A-scan exhibits the front surface and the 1/4-depth backscatter signals in sharper detail than does the $0.5 \mathrm{MHz}$ record. However, detall from the right half of the specimen is lost to attenuation. These two A-scans illustrate the trade off associated with choice of transducer frequency.

In figure $5(b)$ the specimen has been turned around such that the edge that had been on the left is now on the right. Now the plane of high porosity is $3 / 4$ back from the left, or outside diameter, side, with ultrasonic pulse still coming from the left. The $0.5 \mathrm{MHz}$ A-scan now exhibits an internal backscatter $3 / 4$ from the left side, thus supporting the assumption that the highly porous plane is its source. Attenuation in the $1 \mathrm{MHz}$ A-scan is so great that the backscatter is undetectable at $3 / 4$ of the distance through the thickness.

Figure 6 exhibits three $C$-scans produced by gating the front $1 / 3$, the middle $1 / 3$, and the back $1 / 3$ of a time sweep similar to the A-scans just discussed. White areas are due to high backscatter in the area gated. High backscatter in a region close to the front does not obscure backscatter in a region behind it. This fact is demonstrated in the areas circled in figure 6 . The areas exhibit backscatter in each thickness segment independent of the others.

\section{Density and Velocity Specimens}

Three adjacent sets of specimens were cut from segment 1 and two adjacent sets from segment 2 in accordance with the scheme shown in figure 7 . In all, there were nine specimens from segment 1 and seven usable specimens from segment 2. These specimens were used to determine representative density and velocity variations laterally and through the thickness of the segments. Note that shaping of flat specimens with square corners accounts for the fact that the sum of the specimen thicknesses is considerably less than the segment thickness. Detailed radiographs of some of these specimens appear in figure 8 where the contrast between the characteristics of segment 1 and 2 material is evident.

\section{Bend Specimens}

Upon completion of density and velocity measurements, the previously described segment 2 specimens were further cut to produce 12.7 by 1.27 by $0.64 \mathrm{~cm}$ bend test specimens, figure 9 . Twenty bend specimens were made and tested in three-point bending. Each bend specimen contained a total of about five interleaved hoop and helical layers. Because of their small size and orientation relative to the axis of the segment (see fig. 7) and because of the large radius of curvature of the segment, the individual layers in the bend specimens exhibited negligible curvature and could be taken as being essentially flat and parallel. 


\section{INSTRUMENTATION}

An overall view of the velocity measuring instrumentation appears in figure 10. Water immersion provided coupling between specimens and transducers. Ultrasonic signals were detected by a transducer and were amplified and then displayed on a digitizing oscilloscope. From there the waveform was transmitted to a minicomputer for processing. Through transmission ultrasonic measurements were performed with a pair of $1 \mathrm{MHz}$ transducers as sender and receiver. The objective of these measurements was to determine ultrasonic velocity values in segments and in cut specimens. Both through-specimen and water path signals were collected on the same sweep and delay setting. The cross-correlation algorithm was employed to determine the time difference of arrival of the two paths (ref. 14).

Acousto-ultrasonic measurements were performed on bend test specimens using a sensor fixture with two transducers. The sender was a $2.25 \mathrm{MHz}$ pulser transducer and the receiver was a $375 \mathrm{kHz}$ resonant acoustic emission sensor. Silicon rubber dry couplant pads were cemented to the $0.64 \mathrm{~cm}$ diameter wear plates of the transducers. The pads were used to demonstrate the utility in place of gel type couplants which are inconvenient. The specimens were clamped between the transducers and a jack with adjustable force set at $12 \mathrm{~N}$. The fixture-specimen-jack arrangement is shown in figures 11 and 12 .

\section{EXPERIMENTAL TECHNIQUE}

\section{Velocity Measurements}

In the case of experiments on small specimens cut from the segments, ultrasonic velocity measurements were performed by through transmission in a water bath employing two $1 \mathrm{MHz}$ broad band transducers. Each of the nine velocity specimens from segment 1 were measured three times at the same place. The average for each specimen is used in the results along with the standard deviation derived from them. Segment 2 specimens had the larger surface areas. velocities were determined three times at each of three positions and average values and standard deviation were determined.

\section{Density Measurements}

Specimens were parallelepipeds. Densities were determined by measuring dimensions and weight. All weights were determined prior to immersion in water for ultrasonic velocity measurement.

\section{Acousto-uitrasonic Measurements}

As with the velocity measurements, pulses arriving at the receiver were displayed and digitized on the oscilloscope. From there they were transmitted to the computer for processing. The signal energy is defined as the square of the amplified transducer output voltage integrated over the time of the sweep. This was used as stress wave factor. Data was taken at $1.9 \mathrm{~cm}$ intervals. The transducer spacing was $3.8 \mathrm{~cm}$ thus producing a 50 percent overlap between adjacent positions. 
The bend tests were performed by the three point contact method with a standard tensile test machine. The stress-strain records were used to calculate three mechanical properties as follows (ref. 15):

Interlaminar shear strength $=3 \mathrm{P} / 4 \mathrm{bd}$

Ultimate flexure strength $=3 \mathrm{PL} / 2 \mathrm{bd}^{2}$

Tangent modulus of elasticity $=\mathrm{L}^{3} \mathrm{~s} / 4 \mathrm{bd} \mathrm{d}^{3}$

where,

$P$ maximum load, $N$

b width of specimen at mid-span, m

$d$ thickness of specimen at mid-span, m

$\mathrm{L}$ support span, $\mathrm{m}$. $\mathrm{L}=0.0127 \mathrm{~m}$ for $\mathrm{a} 11$ specimens

$s$ slope of tangent at initial straight line portion of load-deflection curve, $\mathrm{N} / \mathrm{m}$

Each specimen was stressed to failure. Orientation of bend tests relative to acousto-ultrasonic measurements is shown in figure 12 .

\section{RESULTS}

\section{Velocity and Density}

Figure 13 shows specimen density versus the distance of its center from the inside diameter surface of the original segment. The horizontal bars represent the thickness of the specimen rather than the error in determining position which is smaller. The data are presented this way because density and velocity are necessarily averages through specimen thickness. The density near outside diameter side of segment 1 is about 3 percent lower than the rest of the thickness. No significant dependence on lateral position is evident. The correlation of these two variables in segment 2 is not as clear as it was with segment 1 . However the density here appears to increase with distance through the thickness from the inside diameter surface. This is opposite the behavior with segment 1 .

Similarly figure 14 shows the measured ultrasonic velocity of the same segment 1 specimens as functions of distance from inside diameter surface. As with density, the velocity is lower toward the outside diameter side and appears not to depend on the lateral position. Segment 2 correlation of velocity with distance is even less apparent than with segment 1.

Figure 15 is the combined plot of ultrasonic velocity versus density. The data for each segment were treated separately with linear regression analysis, references 16 and 17 . The solid lines are the least squared curves and the dashed lines represent one standard deviation of the data about the curves. For segment 1 the analysis gave 


$$
V=(-0.191 \pm 0.100)+(0.310 \pm 0.067) \rho \mathrm{cm} / \mu \mathrm{s}
$$

with $R^{2}=71.8$ percent.

For segment 2 the analysis gave

$$
V=(-0.284 \pm 0.116)=(0.382 \pm 0.080) \rho \mathrm{cm} / \mu \mathrm{S}
$$

with $R^{2}=78.2$ percent.

Here $V$ is velocity and $\rho$ is density. $R^{2}$ is the percent of the variation in the independent variable that is explained by the variation of the dependent variable along the regression curve, reference 18 .

Both thermal mechanical analysis (TMA) and differential scanning calorimetry (DSC) were carried out on some velocity specimens to search for differences in cure state between the two segments. Table II shows TMA results. Higher glass transition temperature corresponds to more complete cure of the epoxy.

\section{Acousto-ultrasonic and Mechanical Properties}

Acousto-ultrasonic SWF measurements were performed on bend test specimens prior to bending them to fallure. Figure 12 shows the relative orientation of these measurements and the subsequent bending. The following combinations of SWF were calculated:

(1) SWF for position 3

(2) SWF averaged over positions 2 through 4

(3) SWF averaged over positions 1 through 5

The following orientations for each of the above were tabulated:

(1) SWF on the concave side

(2) SWF on the convex side

SWF was calculated for each of four bands of the frequency spectrum. The FFT algorithm, reference 19, used with these data produced a 0 to $1 \mathrm{MHz}$ spectrum from a $500 \mu \mathrm{s}$ time record of the acousto-ultrasonic signal. The spectrum was divided into four $0.25 \mathrm{MHz}$ filter bands. Figure 16 is a typical frequency spectrum of an acousto-ultrasonic signal obtained on a specimen. It shows the four equal width filter bands. Figure 17 shows acousto-ultrasonic time domain signals for a typical specimen. Figure $17(\mathrm{a})$ is a full frequency range signal. Figures 17 (b) through (e) show signals reconstructed from the frequency filter bands. This reconstruction was accomplished by zeroing the FFT magnitude and phase of the original signal for frequencies outside the filter range of interest. The resulting arrays were transformed back to produce the filtered time domain signal.

Thus a total of thirty combinations of SWF were tabulated and regressed, (ref. 16), against each of three mechanical variables. Among these the best correlation was obtained regressing the convex side SWF for the frequency filter band from 0.5 to $0.75 \mathrm{MHz}$ averaged over positions 2 through 4 against 
interlaminar shear strength (ISS). This best correlation had $R^{2}=$ 80.6 percent. The data is plotted in figure 18. Note that the full spectrum as represented in figure 17 (a) contains the 0.5 to $0.75 \mathrm{MHz}$ SWF information. But the relation to ISS is obscured by the much larger signal components from the lower frequencies.

Table III is included in order to emphasize that the relation between ISS and SWF is unique to the filter band 0.50 to $0.75 \mathrm{MHz}$ and to the convex side of the bend specimen. Not shown in table III are the results with tangent modulus of elasticity or ultimate flexure strength (UFS). Their correlations with SWF were similar but $R^{2}$ values were not as high. Table IV summarizes velocity, density, mechanical, and acousto-ultrasonic data for each specimen.

\section{ANALYSIS}

The purpose of this section is to analyse the acousto-ultrasonic data in terms of the geometry of the specimens in order to arrive at a model that explains the results. This may in turn lead to a general application to composite material evaluation beyond the geometry of specially cut specimens from filament wound composites.

Figure 12 shows the way in which all the specimens falled. The fallure occurred near, although not at, the convex surface. Thus the stress wave factor that correlates with ISS is sensitive to the shear strength near the surface of transducer contact.

Figure 19 illustrates ray paths for longitudinal ultrasonic waves that reflect off the back and front surfaces with respect to the transducer positions. It is useful to calculate the time, $T$, it takes, assuming this simple mode of propagation for a pulse to travel from the sending transducer to the receiving transducer:

$$
T=\sqrt{(2 j t)^{2}+(D)^{2} / V L}
$$

Where $j$ is the number of round trips due to back and front reflections, $t$ is the specimen thickness, $D$ is the transducer separation, and $V L$ is the longitudinal wave velocity. Figures $17(\mathrm{a})$ through (e) are time records of acousto-ultrasonic signals recovered from an FWC bend specimen. Figure 17(a) is the record for the full $1 \mathrm{MHz}$ spectrum, shown in figure 16, whereas figures 17(b) through (e) show the records for the four filter bands. Arrival times for $j=1,6$, and 11 are shown in these figures assuming the pulse left the sending transducer at the instant of triggering.

The real situation is more complex due to the presence of shear waves, (ref. 20), and of reflections at planes internal to the composite specimen. Although we assume the initial signal leaving the sending transducer to be pure longitudinal, it will split into a longitudinal and a shear component upon reflecting. Further reflections of both longitudinal and shear waves will result in further splitting into pairs, one of each kind for each incident wave. Reflection at planes internal to the specimen further multiplys the number of ray paths involved in the problem.

In order to make an estimate of the transit time, $T$, with shear waves present it is necessary to employ snell's law for this case 


$$
V_{L} / \sin \left(\theta_{L}\right)=V_{S} / \sin \left(\theta_{S}\right)
$$

where $V_{L}$ and $V_{S}$ are the longitudinal and shear wave velocities in the material and $\theta_{L}$ and $\theta_{S}$ are their angles of reflection.

Table $V$ was constructed with the aid of equation 4 and reference 21 . Both the transit time $T$ and the product of successive reflection coefficients are presented for the cases $j=1$ (one back surface reflection), and $j=2$ (two back - one front surface reflection), and for the specimen and transducer geometry of our experiment. $V_{L}$ was taken as a value typical of the results in this report for graphite/epoxy. $V_{S}$ was not determined experimentally. However the ratio $V_{S} / V_{L}$ was assumed to be the same as for polymethylmethacrylate as was determined from reference 21 . The first two rows of table $V$ are calculations for $j=1$. The remaining rows are for the eight possible combinations with $j=2$. The notation L-S-L-S, for example, is for the ray path that starts longitudinal, reflects as shear, reflects again into longitudinal, and finally again into a shear wave. $T$ is the sum of the four path times. The path times are obtained from the physical distance the ray travels. This is solved transidentally under the constraints equation 4 puts on the relation of $\theta_{\mathrm{L}}$ to $\theta_{\mathrm{S}}$.

Comparison of these values of $T$ with the time records of figures $17(a)$ through (e) shows that this mode of ultrasonic energy propagation with low $j$, arrives in the early part of the acousto-ultrasonic signal.

Allowing reflections at internal planes in the specimens allows other combinations of " $L$ " and " $S$ " ray paths. However for a given order $j$ of multiple reflections these additional ray paths will be no longer and generally shorter than the kind considered in table $V$. Thus these additional ray paths due to internal reflections will also arrive early in the acousto-ultrasonic signal.

Note also that internal reflections tend to cause the ray paths to concentrate on the transducer side of the specimen. This is where, experimentally, the sensitivity to ISS was observed.

One would expect that the bulk of ultrasonic energy traveling in this mode would arrive at the receiver for $j<6$. However most of these time records exhibit greatest amplitudes of signal beyond $j=6$. Figure $17(\mathrm{f})$ is a through transmission record of the sender pulse. It is less than 50 us long and can not account for the long acousto-ultrasonic records of figures 17 (a) through (e) by its own length. Among these, only figure $17(\mathrm{~d})$, the 0.50 to $0.75 \mathrm{MHz}$ record, has greatest signal amplitudes between $j=1$ to 6 . The other frequency ranges appear to be dominated by some other mode of propagation since they are strongest at longer times.

Sensitivity to interlaminar shear strength and sensitivity to the front and back surface reflection mode of propagation both occur in the 0.50 to $075 \mathrm{MHz}$ frequency band. It is likely, therefore, that it is this particular mode of ultrasonic wave propagation in the FWC that contains the sensitivity to mechanical strength. These ultrasonic waves sample interlamina strength from front to back of the specimens and must respond to some average through the thickness. They also do not differentiate between measurements on the convex and concave sides. The A-scans, however, show that considerable ultra sonic energy reflects internal to the composites. The waves carrying this 
energy would be weighted towards sampling interlamina strength on the side of transducer contact.

The acousto-ultrasonic waveforms presented in figure 17 show that much more ultrasonic energy arrives at the receiving transducer than the few back and front reflections discussed to this point. This other energy travels a greater time. Figure 17 suggests it is subject to greater attenuation in the 0.5 to $0.75 \mathrm{MHz}$ range. This may in part explain the frequency dependence in the relationship to ISS. The 0.5 to $0.75 \mathrm{MHz}$ filter band does not survive long enough to be overwhelmed by the longer path modes of propagation as are lower frequencies. On the other hand, the frequency spectrum in figure 16 shows that the filter band 0.75 to $1.00 \mathrm{MHz}$ does not contain a range of reliable strong signal. One expects that the range of this compromise will depend not only on the material being measured but also on its geometry and on the characteristics of the transducers employed.

It has been established that ultrasonic parameters can be related to mechanical properties and to defect states in composites (ref. 2 and 12). The present results suggest that ultrasonic waves propagated through the lamina planes are sensitive to interlamina strength. This in turn suggests that collection of the ultrasonic signal should be tailored to emphasize this propagation mode. This might be accomplished in the time domain or in the frequency domain depending on the geometry of the composite specimen.

\section{DISCUSSION}

\section{Velocity and Density}

The present work has demonstrated that the density of FWC can vary as much as 3 percent within one cylinder, and more so from one cylinder to another. The variation of density through the thickness has not been associated with a mechanical property. However there is indication that this variation is systematic and may correspond to changes occurring during the filament winding. The variation of density from one cylinder to another has been identified with differences in porosity.

Figure 15 is a combined plot of velocity versus density for the two segments. This linear relation has been observed to be correct for other porous materials such as ceramics (ref. 17). Over the narrow range of these data, however, it is not easy to distinguish between this and other relationships.

The data for the two segments do seem to fall in separate populations. An obvious difference between them is macroscopic porosity. Segment 2 was more porous than segment 1 . This was observed visually along the edges of the specimens. Examples of the porosity can be seen in figure 8 . The light areas on these $x$-ray prints are low density in the material. The light lines are generally void channels that run along fiber winding directions. They are random but overall much more numerous in segment 2 than in segment 1 .

Scanning electron microscopy was employed in samples of various density. No textural or microporosity differences were found among them These segments were fabricated from identical starting materials (ref. 15). Thermal mechani cal analysis (TMA) and differential scanning calorimetry (DSC) measurements revealed no differences in cure state between specimens of different density 
with in the same segment. TMA did, however, suggest that segment 1 was more completely cured than segment 2 (see table II).

Thus two properties, macroscopic porosity and cure state of epoxy are suggested as possible sources of the differences between the segments as revealed in the velocity-density relation.

\section{Acousto-ultrasonics and Mechanical Tests}

The analysis of acousto-ultrasonic and mechanical data of this report has demonstrated the importance of considering the propagation path of the ultrasonic energy. The interlaminar shear strength of the specimens was found to be related to the portion of the acousto-uitrasonic signal that is dominated by waves traveling with a displacement component parallel to interlaminar bonding forces, and concentrated in the region of yield. Examination of other parts of the acousto-ultrasonic signal revealed no correlation to the mechanical properties studied.

This work demonstrates the value of partitioning acousto-ultrasonic signals in the frequency and in the time domains for calculation of stress wave factor. A mechanical property of filament wound graphite/epoxy composite material, the interlaminar shear strength, was found to be related to stress wave factor when calculated for the frequency band 0.5 to $0.75 \mathrm{MHz}$. This relationship was totally obscured for the stress wave factor as traditionally calculated for the ulfiltered signal.

It is not unlikely that these other portions of the acousto-ultrasonic signal relate to other mechanical properties or to flaw states not constdered here. A search for such relations offers the possibility of greatly increasing the usefulness of acousto-ultrasonics in the study of composites.

In the present work it was assumed that shear waves played no part in the ultrasonic-mechanical relation. Admitting them to the analysis would greatly increase the complexity. However it may also facilitate correlation with mechanical properties under some conditions.

\section{CONCLUSIONS}

Acousto-ultrasonic stress wave factor values can be used as predictor of interlaminar shear strength for small bend test specimens cut from composite segments. The sensitivity of stress wave factor to interlaminar shear strength lies in the ultrasonic energy propagated at normal incidence to lamina boundaries. This mode is essentially due to waves traveling normal to the lamina planes.

This work demonstrates the value of partitioning the acousto-ultrasonic signal in the frequency and in the time domain for calculating the stress wave factor. The unpartitioned signal which has traditionally been used to calculate stress wave factor can contain useful information relating to mechanical or material properties but which is not observable.

Uitrasonic velocity in thick filament would composite materials can be measured employing a through transmission method in a water bath with two 
transducers. The more familiar one transducer pulse-echo method is not appro priate for these materials. The most important reason for this is the existence of internal reflections at ply boundaries and pore surfaces. A-scans taken of these materials show that the interval reflections prohibit sufficient isolation of the back surface echos

The ultrasonic velocity in thick filament wound graphite/epoxy composites is an increasing function of the material density. The density may differ up to 3 percent from place to place in a segment. This variation corresponds to a similar variation in velocity. This density variation is through the thickness of the segment and is thus probably caused by changing conditions during the filament winding process such as curing rate of the epoxy or winding tension in the filament. Density is also affected by porosity in the material and possible cure state.

\section{REFERENCES}

1. Vary, A.; and Bowles, K.J.: Ultrasonic Evaluation of the Strength of Unidirectional Graphite Polymide Composites. Proceedings of the Eleventh Symposium on Nondestructive Testing, ASNT, San Antonio, 1977, pp. 242-258.

2. Hayford, D.T.; Henneke, E.G., II; and Stenchcomb, W.W.: The Correlation of Ultrasonic Attenuation and Shear Strength in Graphite Polymide Composites. J. Compos. Mater., vol. 11, Oct. 1977, pp. 429-444.

3. Vary, A.; and Bowles, K.J.: Use of Ultrasonic Acoustic Techniques for Nondestructive Evaluation of Fiber Composite Strength. Proceedings of 33rd Annual Conference, SPI, New York, 1978, Section 24-A, pp. 1-5.

4. Vary, A.; and Lark, R.F.: Correlation of Fiber Composite Tensile Strength with the Ultrasonic Stress Wave Factor. J. Test. Eval., vol. 7, no. 4, July 1979, pp. 185-191.

5. Williams, J.H., Jr; and Doll, B.: Ultrasonic Attenuation as an Indicator of Fatigue Life of Graphite Fiber Epoxy Composites. Mater. Eval., vol. 38, no. 5, May 1980, pp. 33-37.

6. Williams, J.H., Jr.; Nayeb-Hashemi, H.; and Lee, S.S.: U1trasonic Attenuation and Velocity in AS/3501-6 Graphite Epoxy Composite. J. Non-destr. Eval., vol. 1, no. 2, 1980, pp. 137-148.

7. Williams, J.H., Jr.; and Lampert, N.R.: Ultrasonic Evaluation of Impact Damaged Graphite Fiber Composites. Mater. Eval., vol. 38, no. 12, Dec. 1980, pp. 68-72.

8. Schramm, S.W.; Daniel, I.M.; and Hamilton, W.G.: Evaluation of Sensitivity of Ultrasonic Detection of Disbonds in Graphite/epoxy to Metal Joints. 36 th Annual Conference, Reinforced Plastics/composites Institute. Society of the Plastics Industry, New York, 1981, Session 23-D, pp. 1-6.

9. Williams, J.H., Jr.; Yuce, H.; and Lee, S.S.: Ultrasonic and Mechanical Characterizations of Fatigue States of Graphite Epoxy Composite Laminates. Mater. Eval., vol. 40, no. 5, Apr. 1982, pp. 560-565. 
10. Kiraly, L.J.; and Meyn, E.H.: Ultrasonic Scanning System for Imaging Flaw Growth in Composites. Instrumentation in the Aerospace Industry, Vol. 28 Advances in Test Measurement, vol. 19, part 2, Instrument Society of America, 1982, pp. 561-574.

11. Henneke, E.G., II; et a1.: A Study of the Stress Wave Factor Technique for the Characterization of Composite Materials. NASA CR-3670, 1983.

12. Kulkarni, S.B.: NDT Catches up with Composite Technology. Mach. Des., vol. 55, no. 9, Apr. $21,1983, \mathrm{pp} .38-45$.

13. Hemann, J.H.; and Baaklini, G.Y.: The Effect of Stress on Ultrasonic Pulses in Fiber Reinforced Composites. NASA CR-3724, 1983.

14. Hul1, D.R.; Kautz, H.E.; and Vary, A.: Ultrasonic Velocity Measurements Using Phase-Slope and Cross-Correlation Methods. NASA TM-83794, 1984.

15. 1979 Annual Book of ASTM Standards. Part 35, 0 790, pp. 321-330; Part 36, D 2344-76, pp. 374-377.

16. "Minitab Project," Statistics Department, Pennsylvania State University, University Park, Pa. 16802, 1981.

17. Klima, S.J.; et al.: Uitrasonic Velocity for Estimating Density of Structural Ceramics. NASA TM-82765, 1981.

18. Harne11, D.L.; and Murphy, J.L.: Introductory Statistical Analysis. Addison Wesley, 1975, p. 418.

19. Tektronix 4050 Series, R08 Signal Processing ROM Pack 2 (FFT) Manual, Part No. 070-2841-00, Dec. 1980, Tektronix Inc. Beaverton, OR.

20. Karaguelle, H.; Williams, J.H.; and Lee, S.S.: Stress Waves in an Isotropic Elastic Plate Excited by a Circular Transducer. NASA CR-3877, 1985.

21. Krautkramer, J.; and Krautkramer, H.: Ultrasonic Testing of Materials. Translation of second revised german edition, Springer-Verlag, New York, 1969, pp. 476-481. 
TABLE I. - REPRESENTATIVE FILAMENT WOUND COMPOSITE (FWC) SEGMENTSa

\begin{tabular}{|c|c|c|c|c|c|}
\hline \multirow[t]{2}{*}{ Segment } & \multirow{2}{*}{$\begin{array}{c}\text { Source FWC } \\
\text { cylinder }\end{array}$} & \multirow{2}{*}{$\begin{array}{l}\text { Radial } \\
\text { thickness, } \\
\text { cm }\end{array}$} & \multicolumn{3}{|c|}{ Number of winding layers $f$} \\
\hline & & & $\begin{array}{l}\text { Helical, } \\
\pm 30^{\circ}\end{array}$ & $\begin{array}{l}\text { Hoop, } \\
90^{\circ}\end{array}$ & Total \\
\hline $\begin{array}{l}\text { FWC } 1^{b} \\
\text { FWC } 2^{c}\end{array}$ & $\begin{array}{l}C-30-4^{d} \\
D A-003^{e}\end{array}$ & $\begin{array}{l}3.02 \\
3.34 \\
\end{array}$ & $\begin{array}{l}12 \\
16 \\
\end{array}$ & $\begin{array}{l}12 \\
19 \\
\end{array}$ & $\begin{array}{l}24 \\
35 \\
\end{array}$ \\
\hline
\end{tabular}

asegments were cut from graphite/epoxy FWC cylinders fabricated by Hercules under contract to NASA's Marshall Space Flight Center.

bcylindrical FWC segment 1 was 30.5 by $30.5 \mathrm{~cm}(12$ by $12 \mathrm{in})$, approximately.

CCylindrical FWC segment 2 was $30.5 \times 61 \mathrm{~cm}(12$ by $24 \mathrm{in})$, approximately.

dsource of segment 1 was a quarter scale, full wall thickness, $76.2 \mathrm{~cm}$ (30 in) i.d. cylinder designated as $\mathrm{C}-30-4$ by Hercules.

esource of segment 2 was a full scale, full wall thickness, $365.8 \mathrm{~cm}$ (144 in) 1.d. cylinder designated as $\mathrm{DA}-003$ by Hercules.

fhe inner layer starts with one cloth substrate ply. 
TABLE II. - GLASS TRANSITION TEMPERATURES

FOR FWC MATERIAL AS DETERMINED

BY THERMAL MECHANICAL

ANALYSIS

\begin{tabular}{|l|c|c|}
\hline & \multicolumn{2}{|c|}{ Temperature, ${ }^{\circ} \mathrm{C}$} \\
\cline { 2 - 3 } & Segment 1 & Segment 2 \\
\hline Individua 1 & 137 & 112 \\
specimen & 135 & 113 \\
& 129 & 115 \\
& 130 & 115 \\
& 127 & \\
& 142 & \\
& 141 & \\
& 127 & \\
\hline Specimen mean & 134.1 & 113.5 \\
\hline Standard deviation & & \\
from mean & 6.0 & 1.6 \\
\hline
\end{tabular}


TABLE III. - $R^{2}$ PERCENT VALUES FOR LINEAR REGRESSION FIT BETWEEN STRESS WAVE FACTOR (SWF) AND INTERLAMINAR SHEAR STRENGTH (I.S.S.)

\begin{tabular}{|c|c|c|c|c|c|}
\hline \multicolumn{6}{|c|}{ Concave side } \\
\hline & $\begin{array}{l}\text { SWF, } \\
0 \text { to } 0.25 \mathrm{MHz}\end{array}$ & $\begin{array}{c}\text { SWF, } \\
0.25 \text { to } 0.5 \mathrm{MHz}\end{array}$ & $\begin{array}{l}\text { SWF, } \\
0.5 \text { to } 0.75 \mathrm{MHz}\end{array}$ & $\begin{array}{c}\text { SWF, } \\
0.75 \text { to } 1 \\
\mathrm{MHz}\end{array}$ & $\begin{array}{l}\text { SWF, } \\
\text { total }\end{array}$ \\
\hline $\begin{array}{l}\text { Position } 3 \\
\text { Average position } \\
2 \text { to } 4 \\
\text { Average position } \\
\quad 1 \text { to } 5\end{array}$ & $\begin{array}{l}0 \\
0 \\
0\end{array}$ & $\begin{array}{r}9 \\
26 \\
35\end{array}$ & $\begin{array}{l}0 \\
0 \\
0\end{array}$ & $\begin{array}{r}23 \\
18 \\
0\end{array}$ & $\begin{array}{l}3 \\
4 \\
0\end{array}$ \\
\hline \multicolumn{6}{|c|}{ Convex side } \\
\hline $\begin{array}{l}\text { Position } 3 \\
\text { Average position } \\
2 \text { to } 4 \\
\text { Average position } \\
\quad 1 \text { to } 5\end{array}$ & $\begin{array}{l}3 \\
0 \\
11\end{array}$ & $\begin{array}{l}40 \\
36 \\
15\end{array}$ & $\begin{array}{l}66 \\
81 \\
51\end{array}$ & $\begin{array}{l}40 \\
32 \\
28\end{array}$ & $\begin{array}{l}27 \\
31 \\
27\end{array}$ \\
\hline
\end{tabular}


TABLE IV. - SUMMARY OF PHYSICAL, MECHANICAL, AND ULTRASONIC RESULTS FOR CUT SPECIMENS, OF SEGMENT 2

\begin{tabular}{|c|c|c|l|r|}
\hline $\begin{array}{c}\text { Velocity, } \\
\mathrm{cm} / \mu \mathrm{s}\end{array}$ & $\begin{array}{c}\text { Density, } \\
\mathrm{g} / \mathrm{cm}^{3}\end{array}$ & $\begin{array}{c}\text { IFM, } \\
\mathrm{MPa}\end{array}$ & \multicolumn{1}{|c|}{$\begin{array}{c}\text { UFS, } \\
\mathrm{MPa}\end{array}$} & $\begin{array}{r}\text { ISS, } \\
\mathrm{MPa}\end{array}$ \\
\hline 0.273 & 1.426 & 1.65 & $275 \times 10^{2}$ & 799 \\
.267 & 1.443 & 0.67 & 343 & 1068 \\
.270 & 1.440 & .36 & 403 & 1386 \\
.272 & 1.458 & 1.13 & 217 & 707 \\
.266 & 1.436 & .61 & 284 & 909 \\
.260 & 1.433 & .66 & 215 & 677 \\
.271 & 1.455 & .32 & 387 & 1378 \\
.260 & 1.425 & .99 & 214 & 688 \\
.273 & 1.426 & 4.64 & 325 & 881 \\
.267 & 1.443 & 1.44 & 289 & 890 \\
.270 & 1.440 & 1.00 & 399 & 1344 \\
.266 & 1.436 & 1.48 & 355 & 1096 \\
.260 & 1.433 & 1.35 & 143 & 457 \\
.271 & 1.455 & .56 & 367 & 1330 \\
.273 & 1.426 & 4.99 & 349 & 898 \\
.267 & 1.443 & 1.41 & 379 & 1162 \\
.270 & 1.440 & 1.02 & 413 & 1384 \\
.266 & 1.436 & 2.11 & 196 & 592 \\
.260 & 1.433 & 1.16 & 123 & 363 \\
.271 & 1.455 & .58 & 388 & 1408 \\
\hline
\end{tabular}

Stress Wave Factor, Convex Side, Average Positions 2 to 4

\begin{tabular}{|c|c|c|c|c|}
\hline 0 to $0.25 \mathrm{MHz}$ & 0.25 to $0.5 \mathrm{MHz}$ & 0.5 to $0.75 \mathrm{MHz}$ & 0.75 to $1 \mathrm{MHz}$ & 0 to $1 \mathrm{MHz}$ \\
\hline 3.91 & 4.64 & 0.21 & 0.041 & 8.81 \\
7.24 & 2.55 & .17 & .040 & 10.01 \\
6.21 & 5.42 & .29 & .035 & 11.97 \\
6.38 & 5.33 & .16 & .043 & 11.92 \\
6.74 & 2.80 & .15 & .028 & 9.72 \\
2.29 & 5.29 & .13 & .045 & 7.77 \\
5.50 & 7.56 & .42 & .057 & 13.55 \\
4.14 & 3.32 & .16 & .035 & 7.66 \\
2.53 & 2.49 & .13 & .028 & 5.19 \\
3.46 & 3.53 & .22 & .035 & 7.25 \\
3.15 & 6.30 & .28 & .055 & 9.80 \\
7.02 & 4.31 & .25 & .041 & 11.63 \\
0.54 & 1.22 & .02 & .021 & 1.81 \\
1.15 & 4.06 & .35 & .034 & 5.61 \\
2.90 & 4.02 & .16 & .037 & 7.13 \\
5.51 & 1.85 & .18 & .024 & 7.58 \\
3.89 & 9.43 & .38 & .059 & 13.77 \\
6.69 & 3.31 & .13 & .035 & 10.18 \\
1.05 & 1.49 & .04 & .025 & 2.61 \\
2.99 & 5.58 & .39 & .054 & 9.02 \\
\hline
\end{tabular}


TABLE V. - TRANSIT TIME, T, AND CUMULATIVE REFLECTION COEFFICIENT, R, FOR FRONT AND BACK SURFACE REFLECTED ULTRASONIC RAYS IN BEND SPECIMENS

OF FWC MATERIAL. CALCULATIONS ARE FOR $j=1$ AND $j=2$ ROUND TRIPS WITH ALL COMBINATIONS OF LONGITUDINAL "L" WAVES AND SHEAR "S" WAVES

[Transducer sep. $=1.5 \mathrm{in}$, specimen thickness $=0.25$ in long. Velocity $=0.27 \mathrm{~cm} / \mu \mathrm{s}$, shear velocity $=0.14 \mathrm{~cm} / \mu \mathrm{s}$.

\begin{tabular}{|l|c|c|}
\hline $\begin{array}{c}\text { Wave-mode } \\
\text { sequence }\end{array}$ & $\begin{array}{c}\text { Transit time, } \\
\text { T, } \mu S\end{array}$ & $\begin{array}{c}\text { Cumulative reflection } \\
\text { coefficient, } \\
\text { R }\end{array}$ \\
\hline L-L & 15.01 & -0.319 \\
L-S & 18.49 & .288 \\
L-L-L-L & 16.93 & -.041 \\
L-L-L-S & 19.76 & .046 \\
L-L-S-L & 19.76 & .276 \\
L-S-L-L & 19.76 & .276 \\
L-L-S-S & 22.76 & .039 \\
L-S-L-S & 22.76 & -.414 \\
L-S-S-L & 22.76 & .268 \\
L-S-S-S & 26.02 & .052 \\
\hline
\end{tabular}




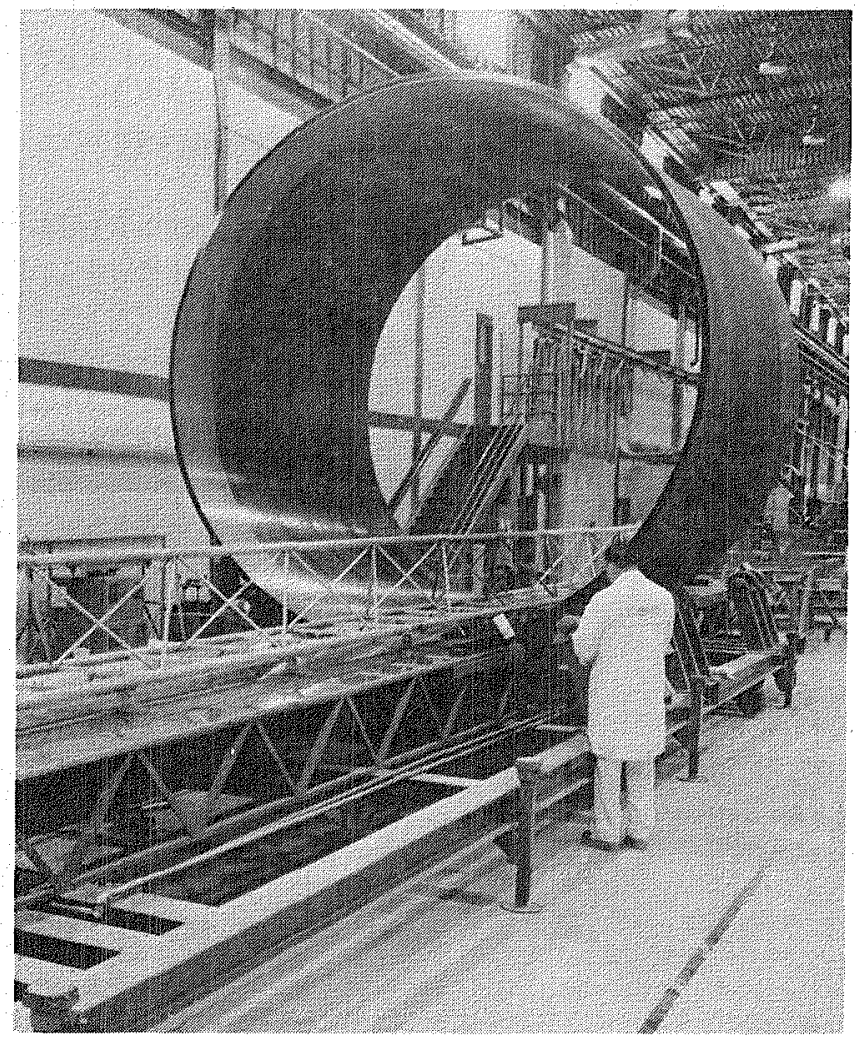

Figure 1. - Filament wound composite (FWC) cylinder in ultrasonic testing facility。 One of four similar sections that will comprise the FWC reusable booster cases for the space shuttle. Computer automated ultrasonic scans are made by several sets of transducers submerged in a shallow tray of water. During scanning the cylinder rotates. (Courtesy J. Kordig, Hercules, Mag ua, Utah) 


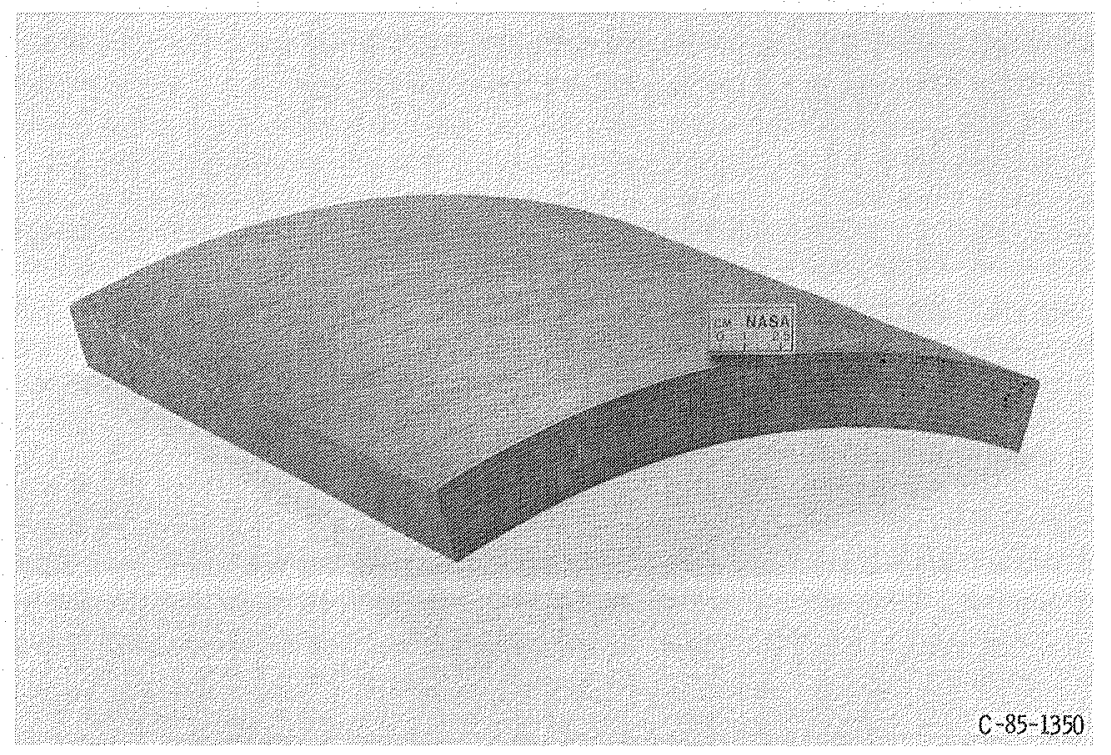

(a) Segment 1 (from cylinder C-30-4b

Figure 2 - Views of segments 1 and 2 from FWC cylinders.

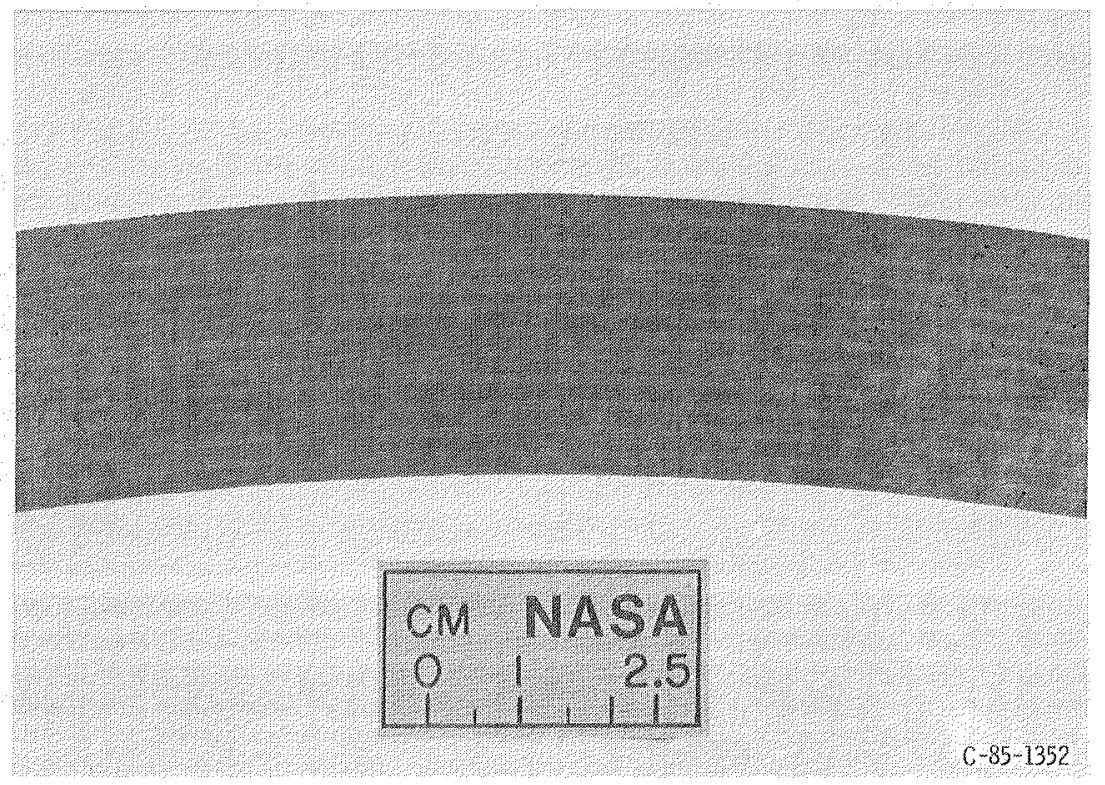

(b) Edge view of segment 1.

Figure 2。 - Continued 


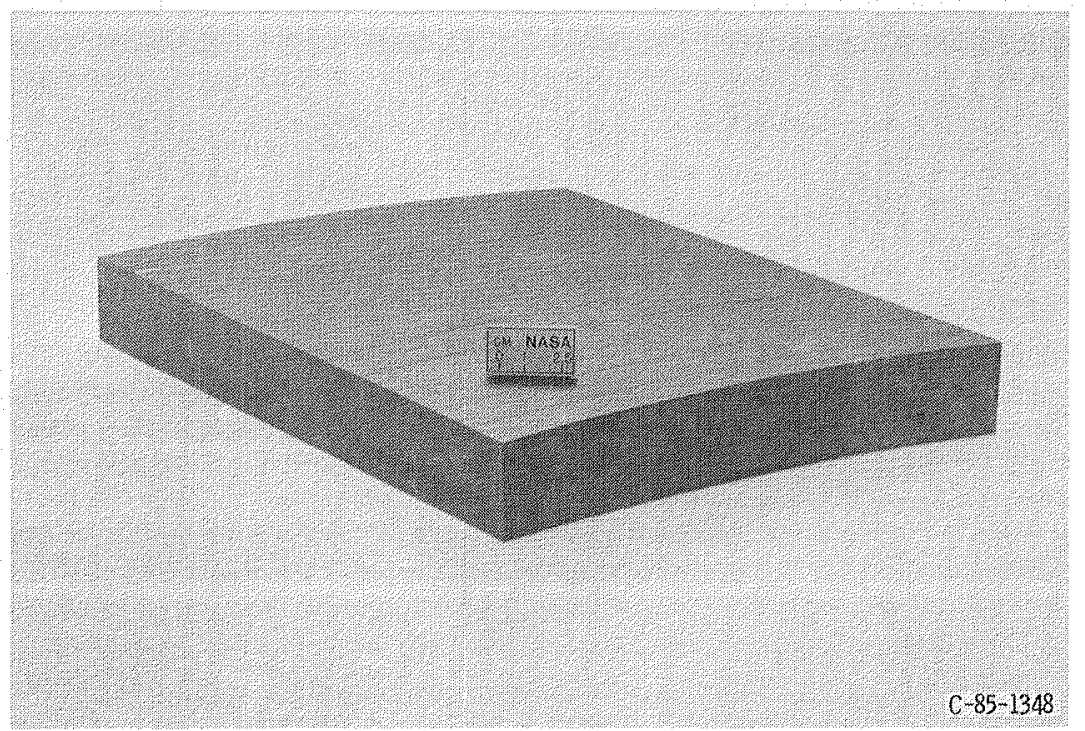

(c) Segment 2 (from cylinder DA-003).

Figure 2. - Continued.

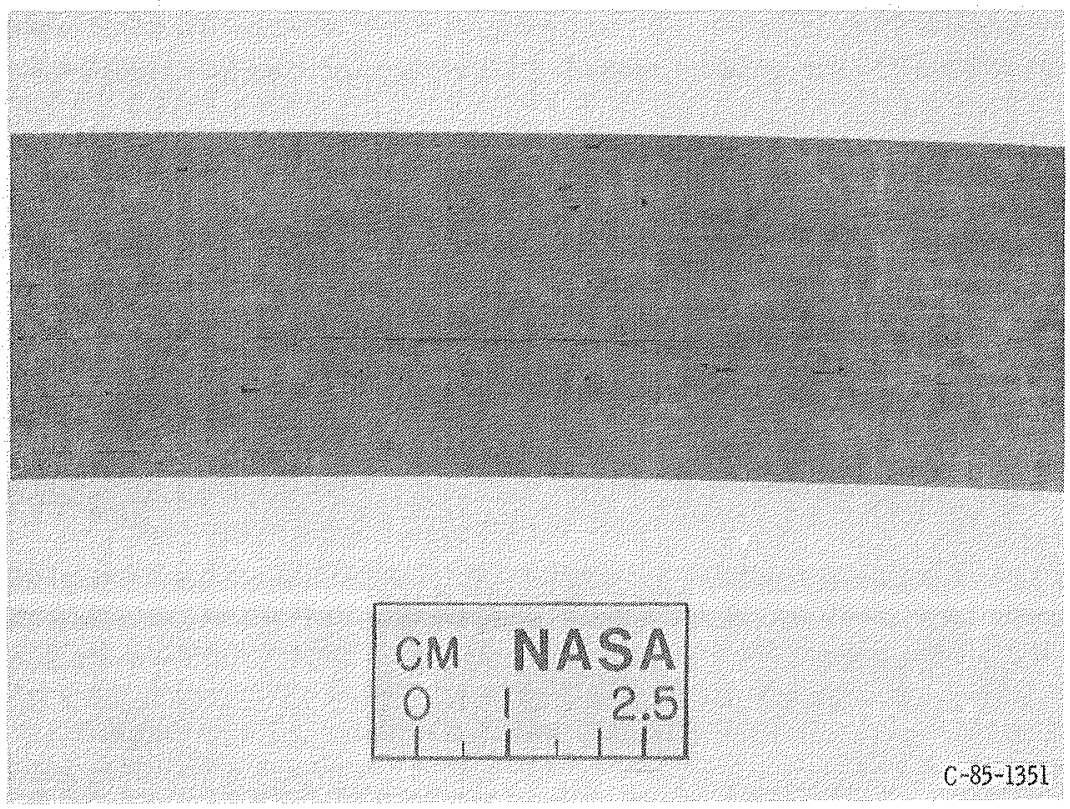

(d) Edge view of segment 2 .

Figure 2. - Concluded。 


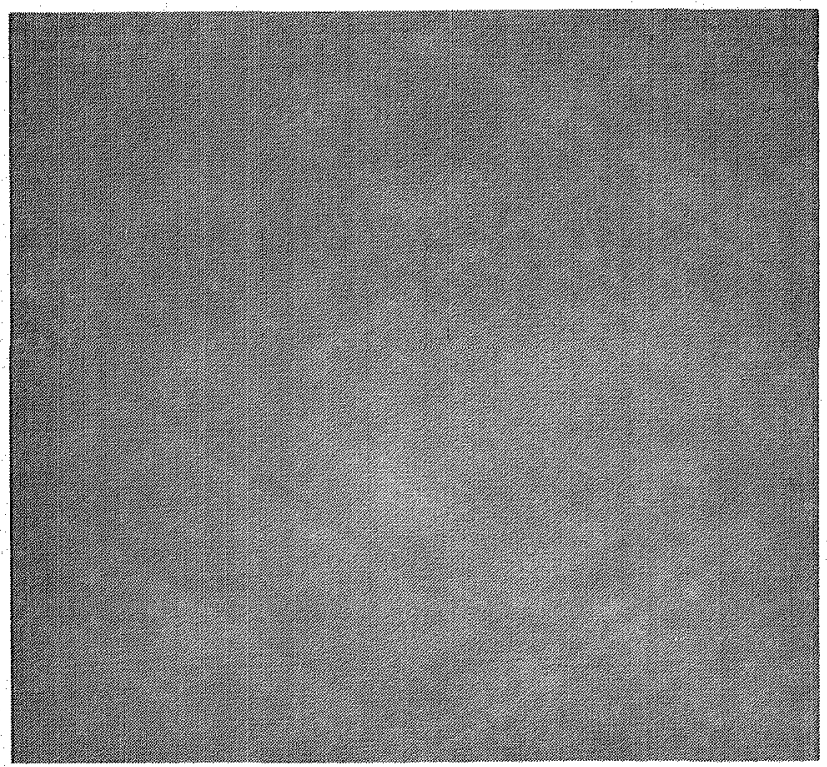

(a) Segment $l_{\text {。 }}$

Figure 3. - Prints of radiographs of FWC segmenis.

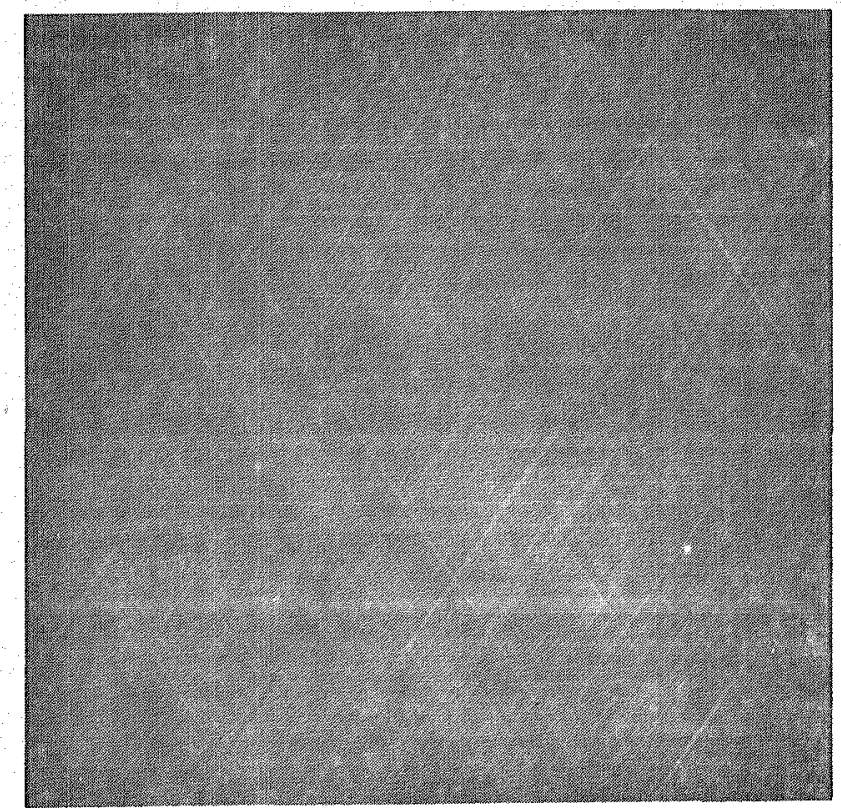

(b) Segment 2.

Figure 3. - Concluded。 


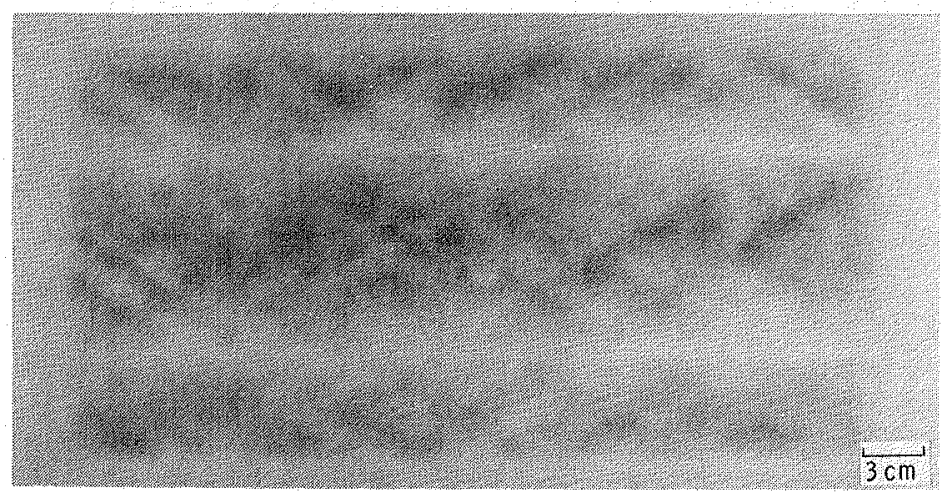

(a) Segment $1, c-30-4$.



(b) Segment 2, DA-003.

Figure 4. - Represntative immersion ultrasonic C-scans. Center frequency of sending and recieving transducers was $1 \mathrm{MHZ}$. Darker areas are greater transmission。 
Pulse

echo

transducer -2 -

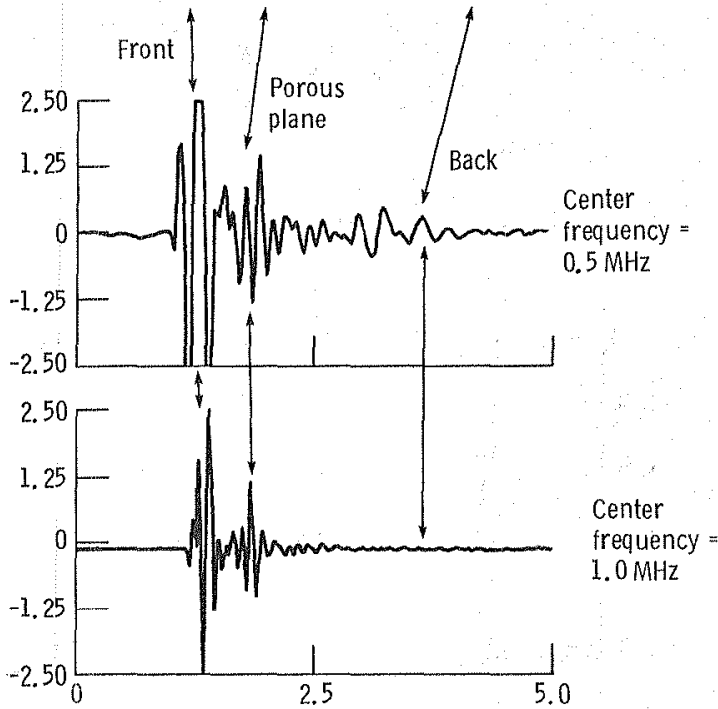

(a) Porous interface near front surface.

Figure 5. - Edge view of FWC section with porous interface compared with ultrasonic A-scans. 


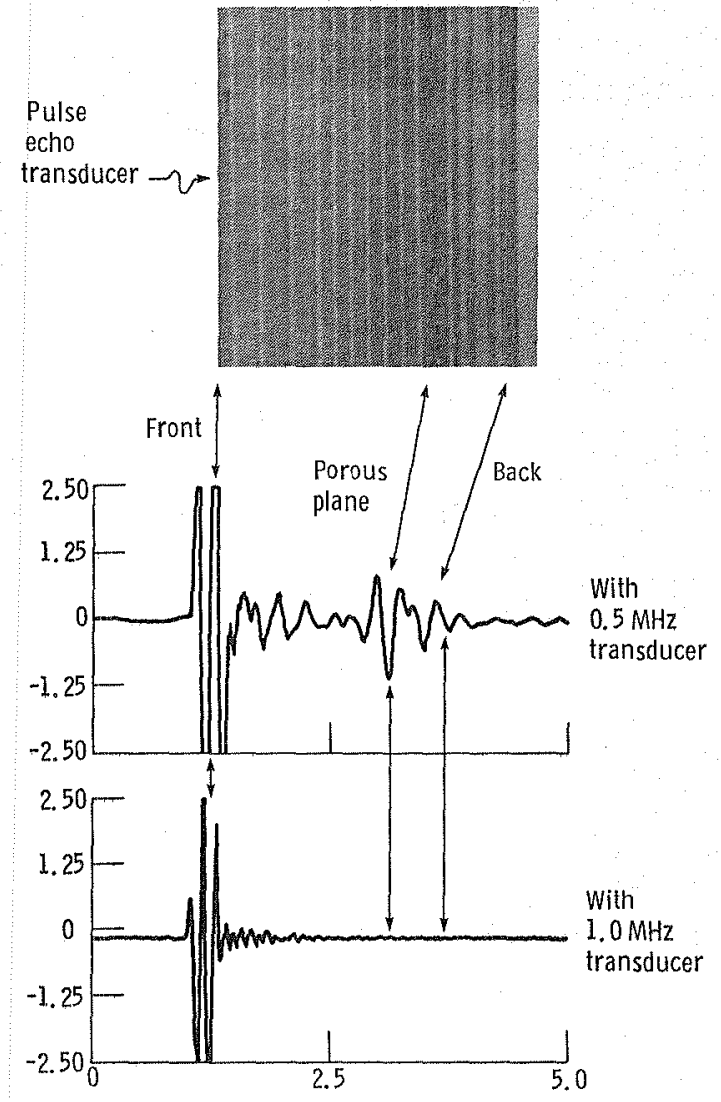

(b) Porous interface remote from front surface.

Figure 5. - Concluded. 

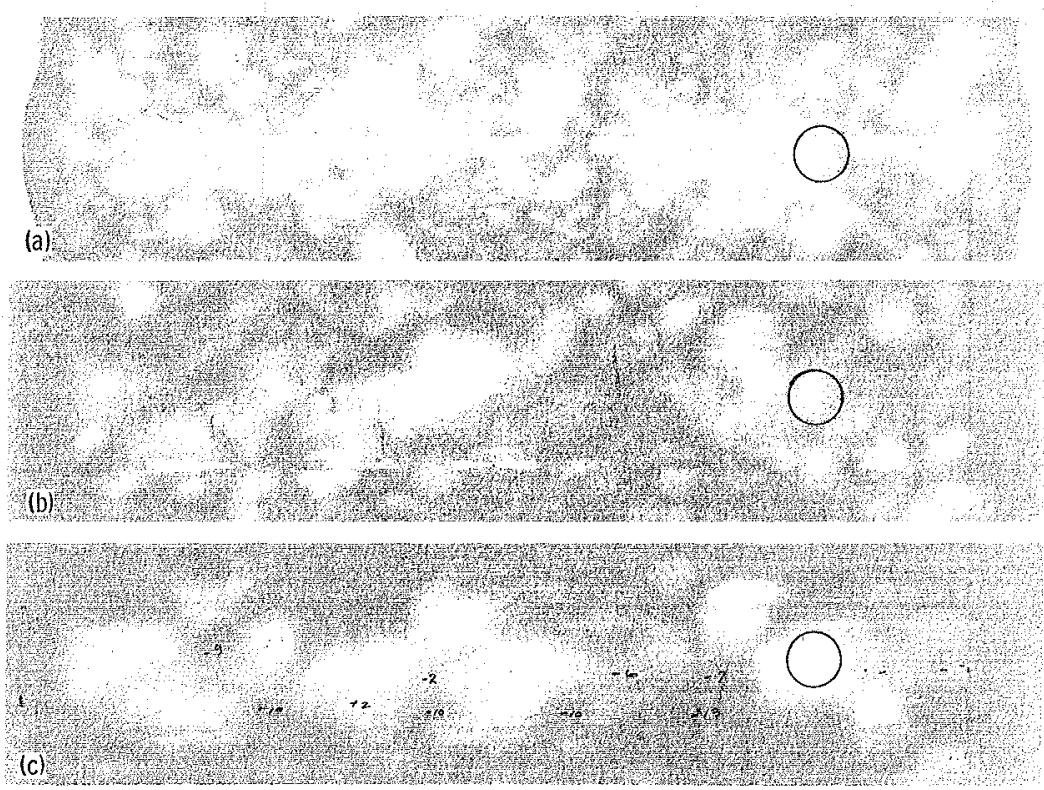

(a) Backscatter from top $1 / 3$

(b) Backscatter from middle $1 / 3$.

(c) Backscatter from bottom $1 / 3$.

Figure 6. - Backscatter C-scans of segment 1 at $0.5 \mathrm{MHZ}$ with (a) top $1 / 3$ layer, (b) middle $1 / 3$ layer, (c) bottom 1/3 layer imaged by appropriate gating of A-scan. Note that each layer is transparent to backscatter from successive layers as in encircled area. (White areas are backscatter echos.) 


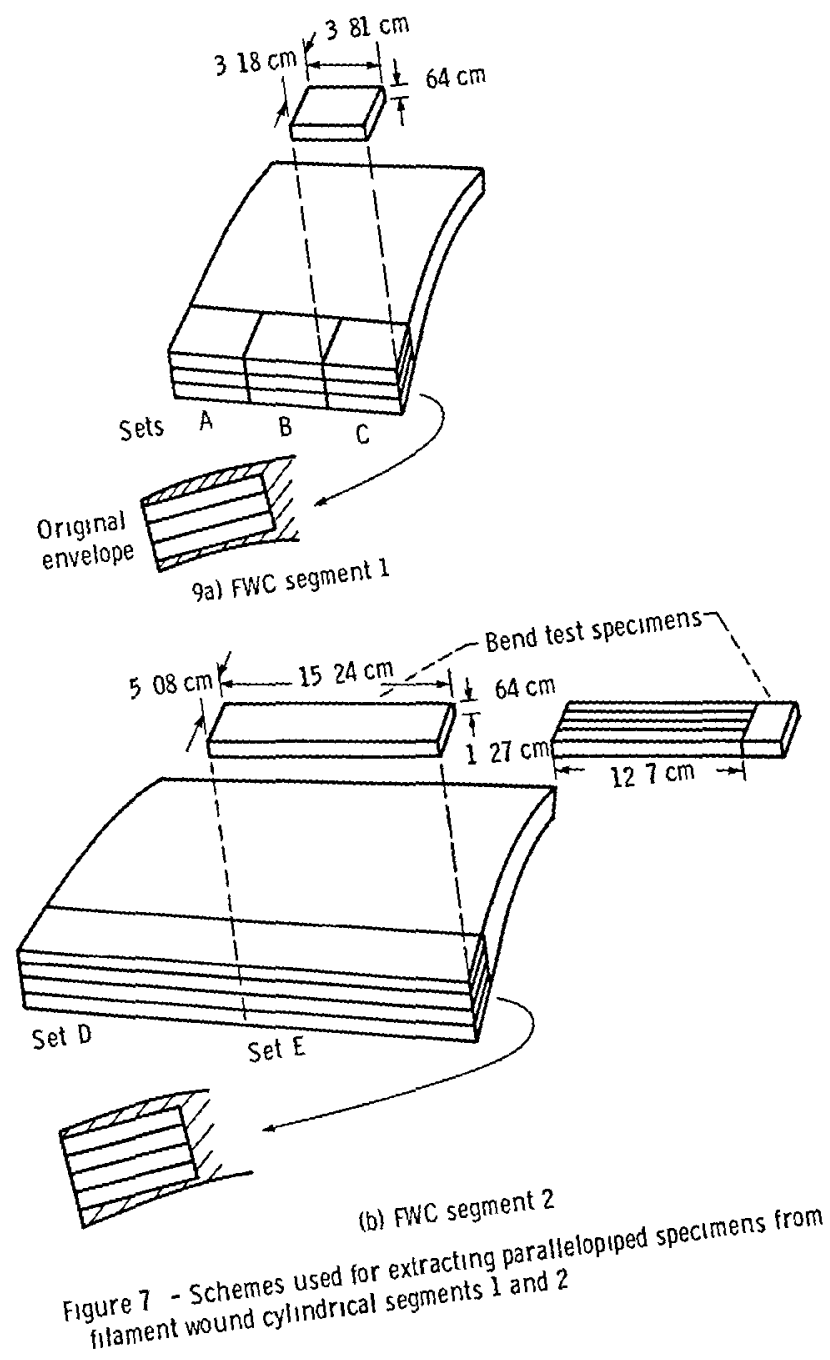


SET A
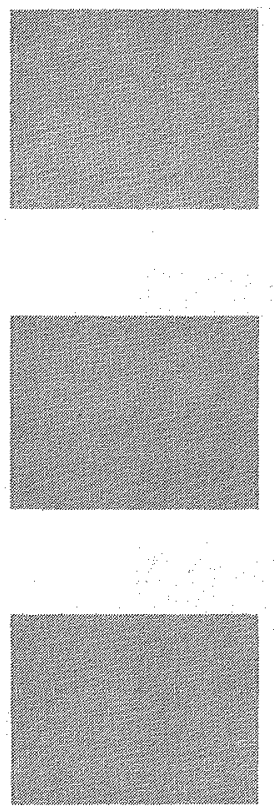

SET B
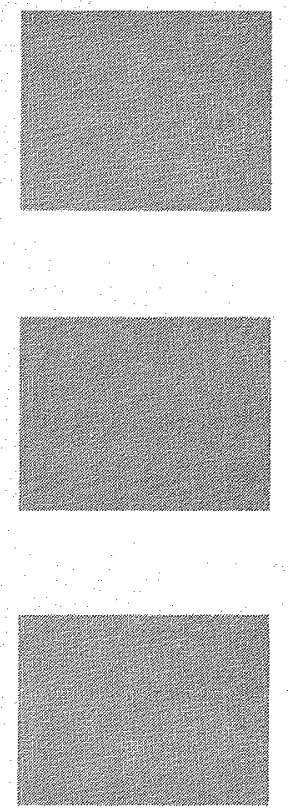

SET C

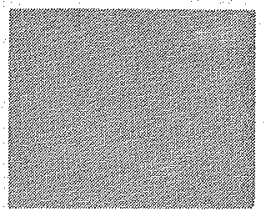

O.D. SIDE

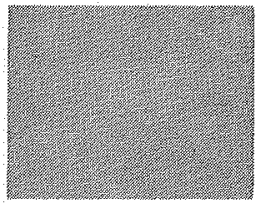

MIDDLE

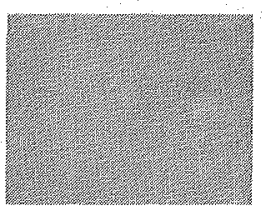

(a) Specimens from segment $1, c-30-4$.

Figure 8. - Positive prints of $x$-radiographs of specimens cut from segments 1 and 2 illustrating differences in the nature of porositylvoid distrubution. Refer to figure 7 for specimen locations in the segments. 
SET E

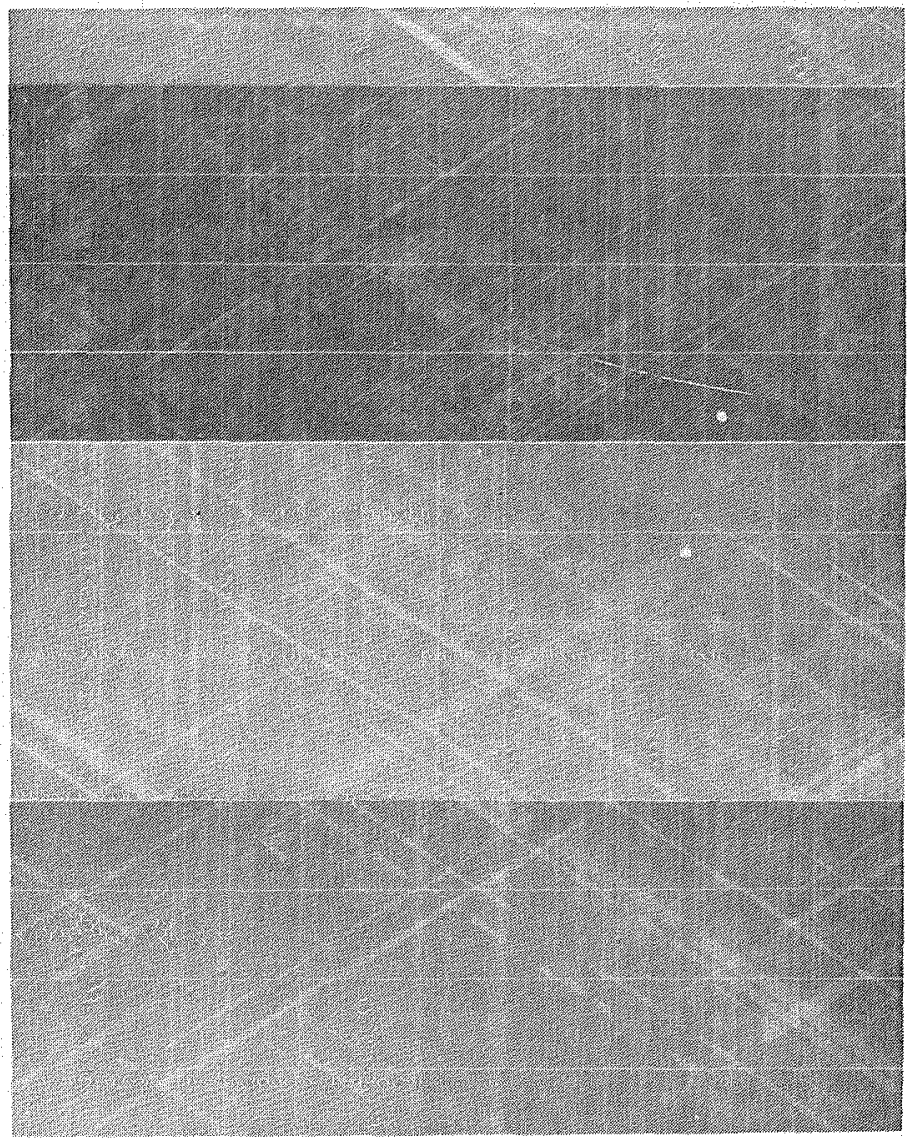

O. D. SIDE

(b) Specimens from segment 2, DA-003.

Figure 8. - Concluded.

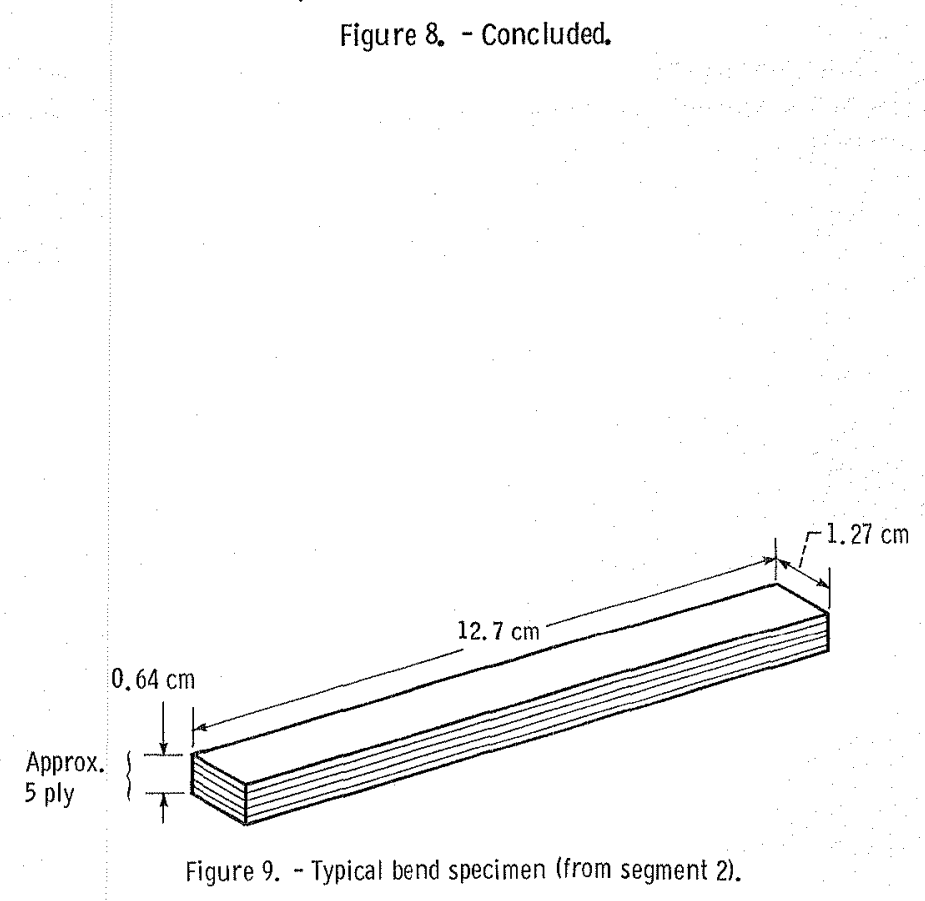




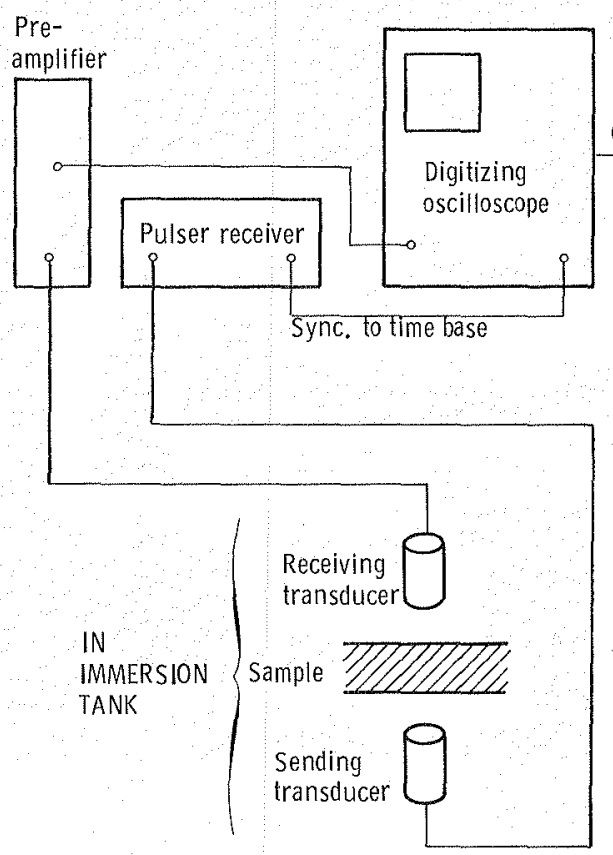

Through transmission

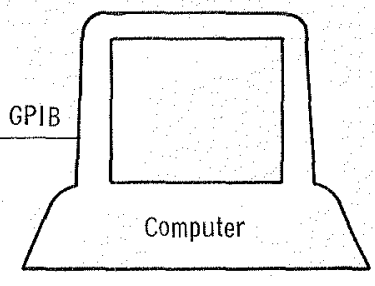

Tank

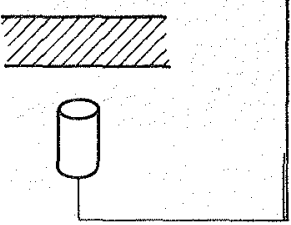

Pulse-echo

Figure 10. - Schematic for sending, collecting, and digitizing signals for computer processing.

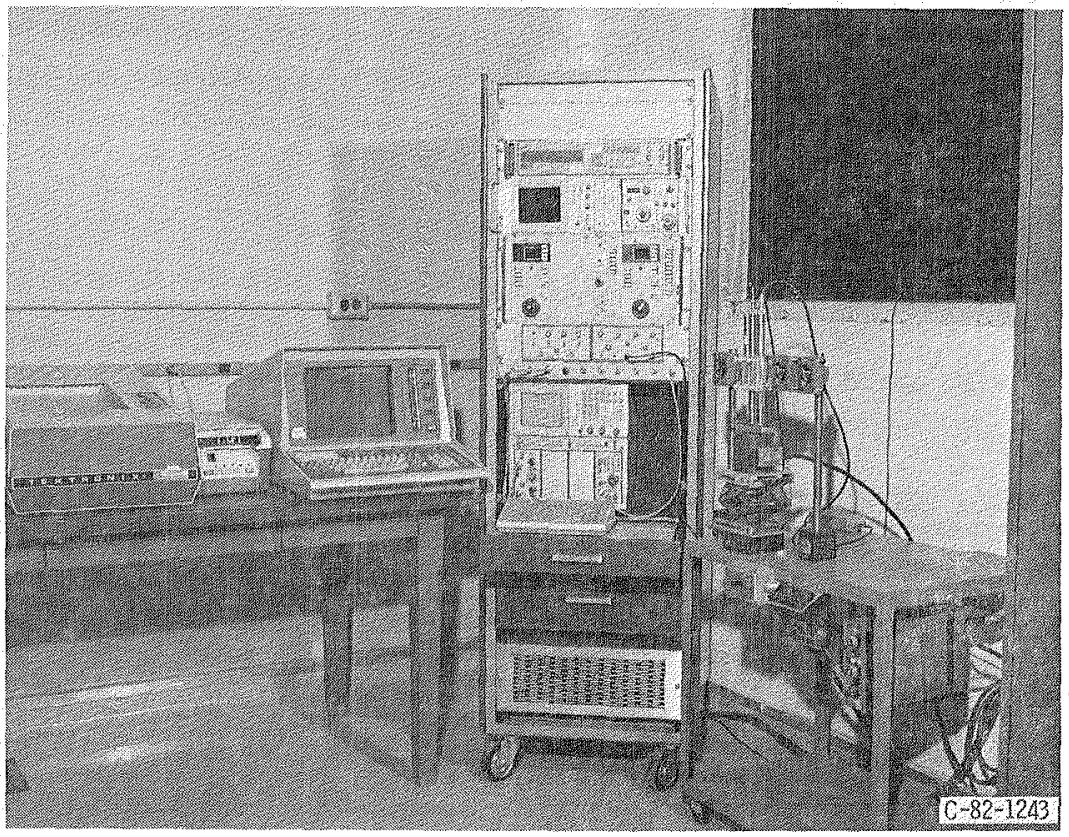

(a) Overall system.

Figure 11. - Instrumentation for Acousto-ultrasonic measurements. 


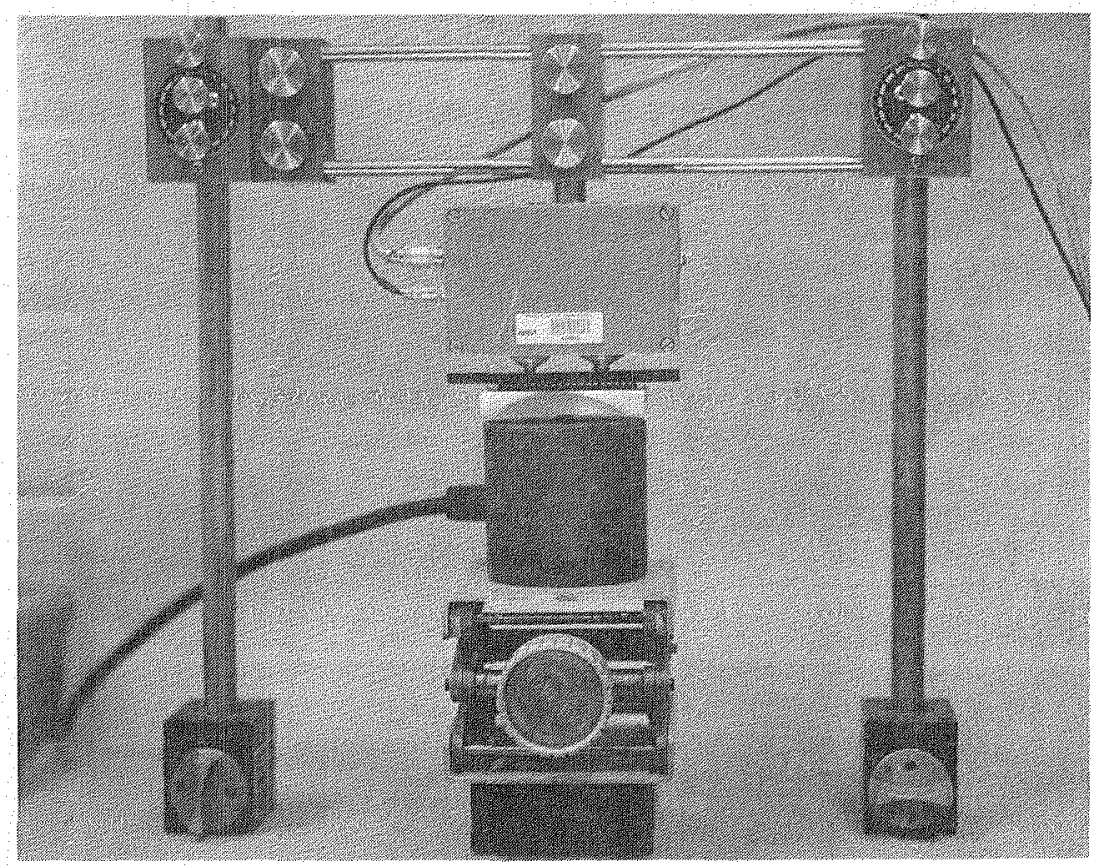

(b) Close-up of fixture - specimen jack arrangement.

Figure 11. - Concluded.

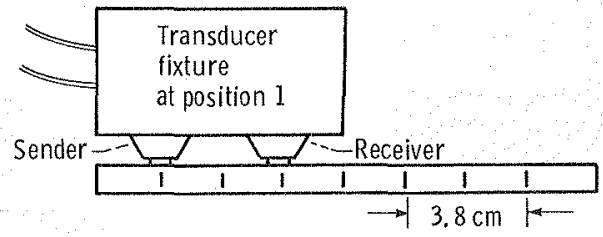

Concave positions

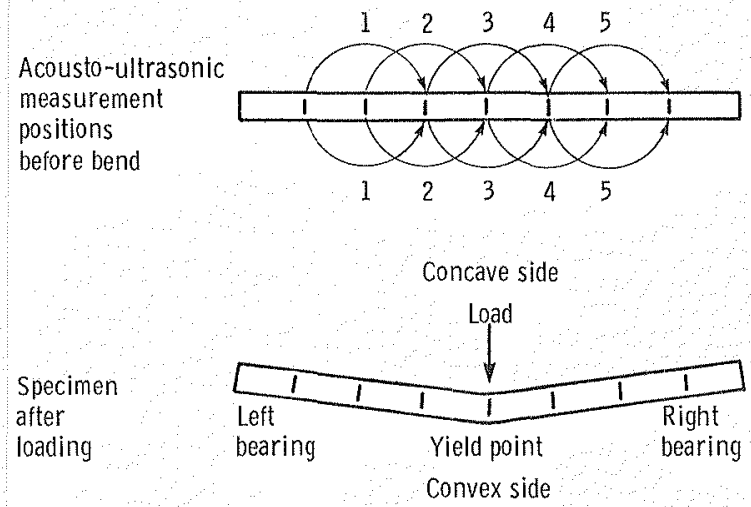

Figure 12. - Diagram of a bend test specimen illustrating the relative orientation of acousto-ultrasonic measurements and bend test. support points. Acousto-ultrasonic measurements were made on both concave and convex sides. 


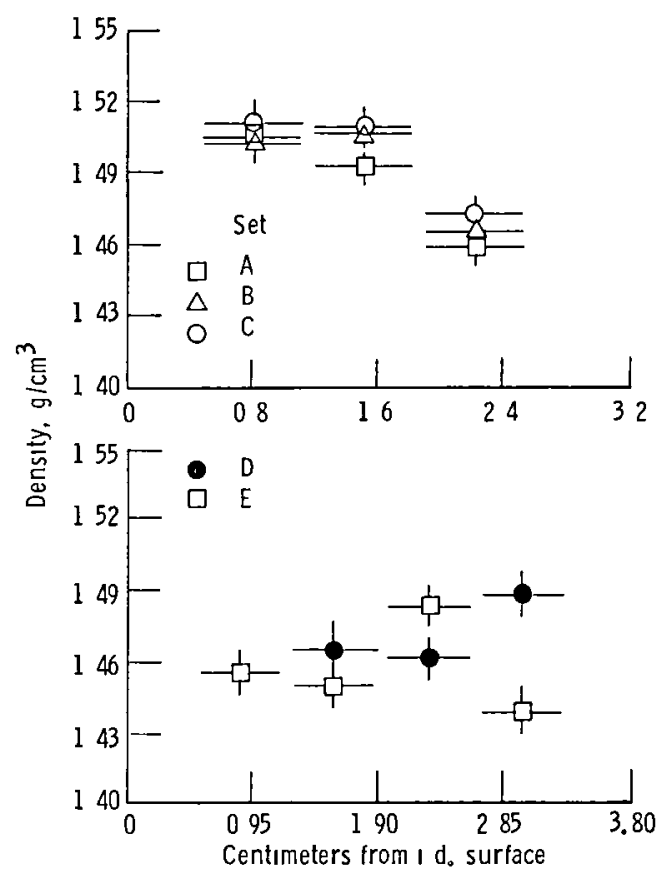

Figure 13 - Representative variation of composite density as a function of distance from inside diameter (I.d) surface of cylinder segments $l$ and 2

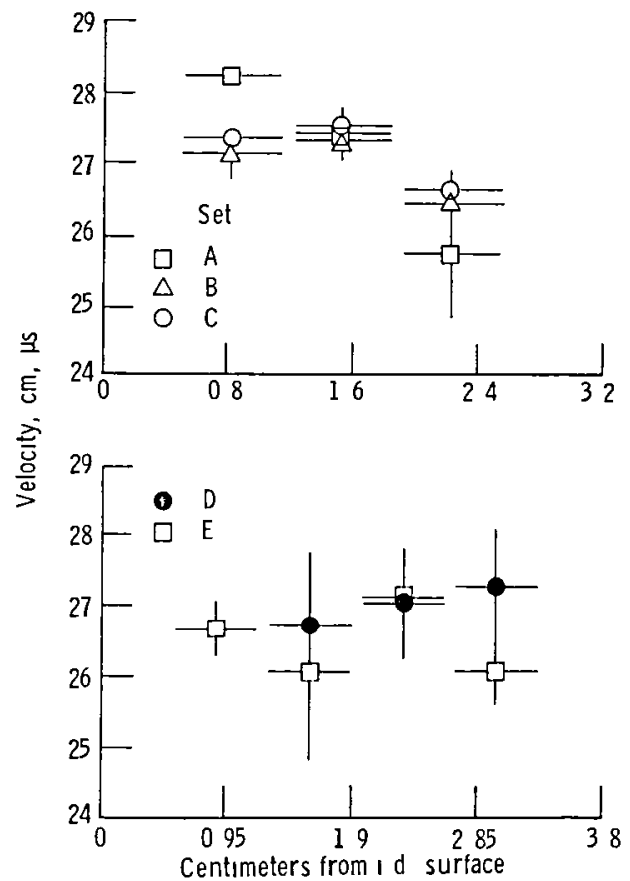

Figure 14 - Representative variation of ultrasonic velocity as a function of distance from Inside diameter $(1, d$.) surface of cylinder segments 1 and 2 


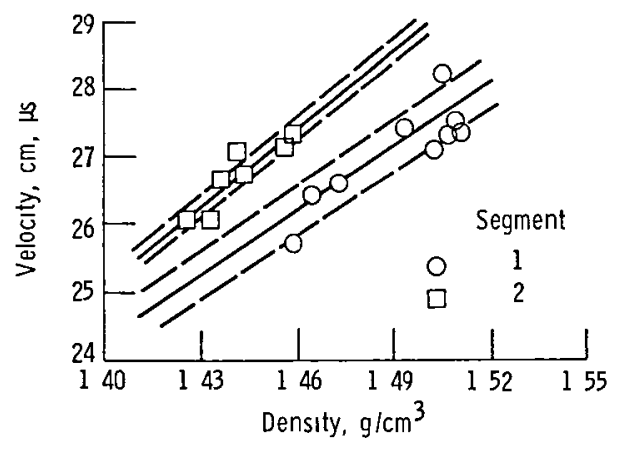

Figure 15 - Velocity versus density for segments 1 and 2 Dashed lines represent one standard deviation from the regression curves

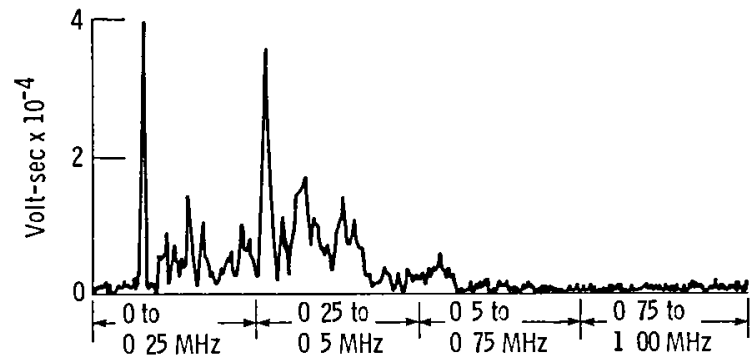

Figure 16 - Magnitude of the Fourier spectrum for a typical bend specimen acousto-ultrasonic signal Also shown are the four filter bands used in the analysis 

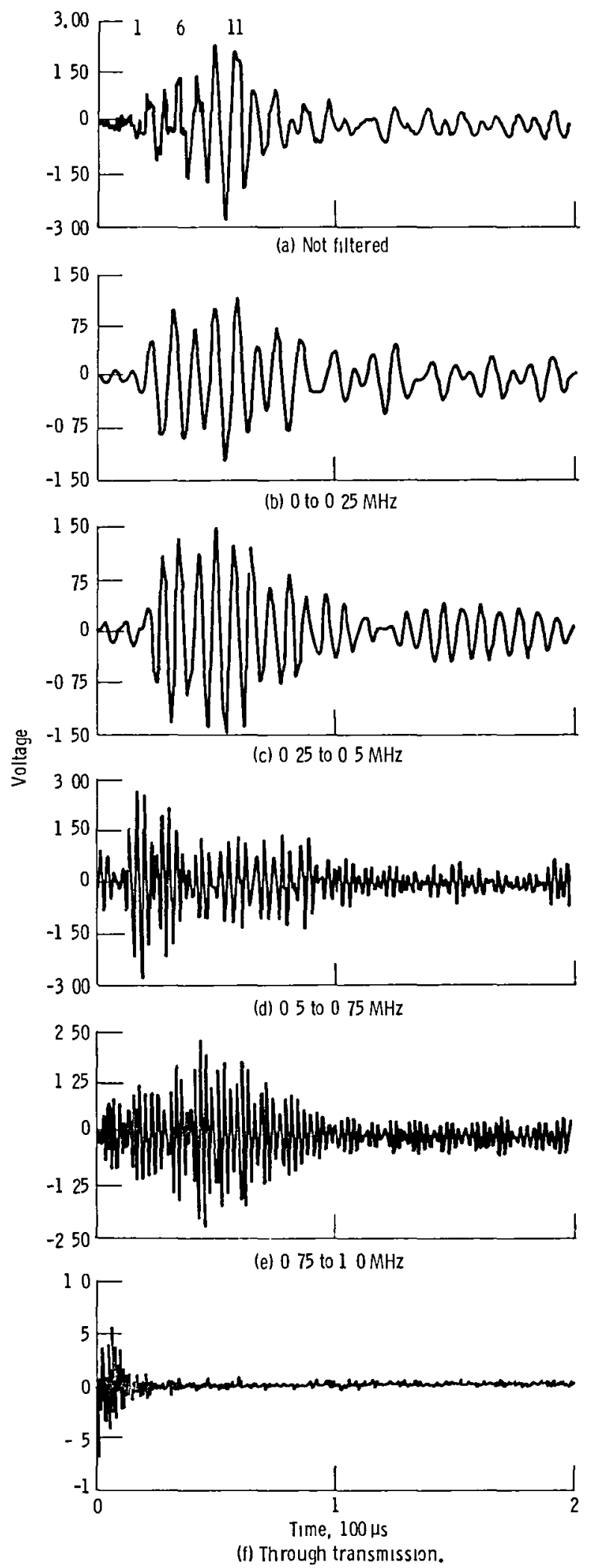

Figure 17 - Frequency filtered acousto-ultrasonic sıgnal from FWC bend specimen 


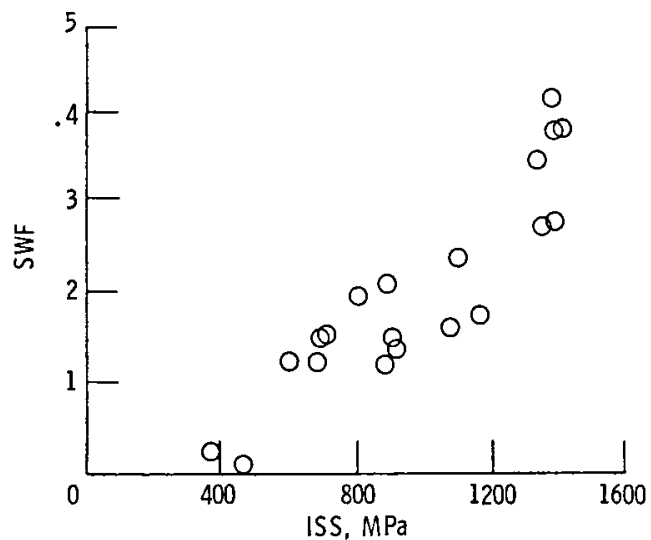

Figure 18 - Stress wave factor for the frequency range 05 to $075 \mathrm{MHz}$ averaged over positions 2 through 4 versus interlaminar shear strength $R^{2}=806$ percent for this data

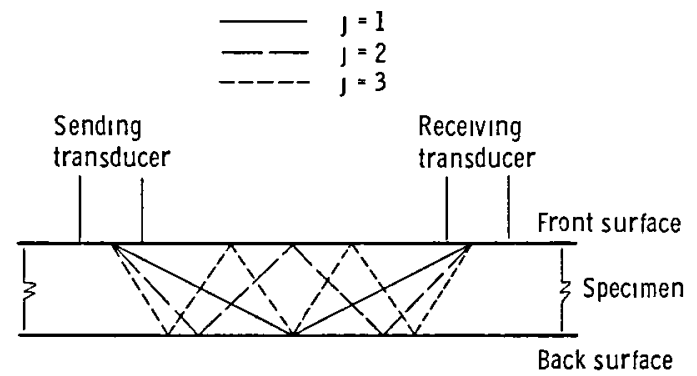

Figure 19 - Ray paths for simple back surface and front surface reffection longitudinal wave propagation mode in FWC bend test specimens 


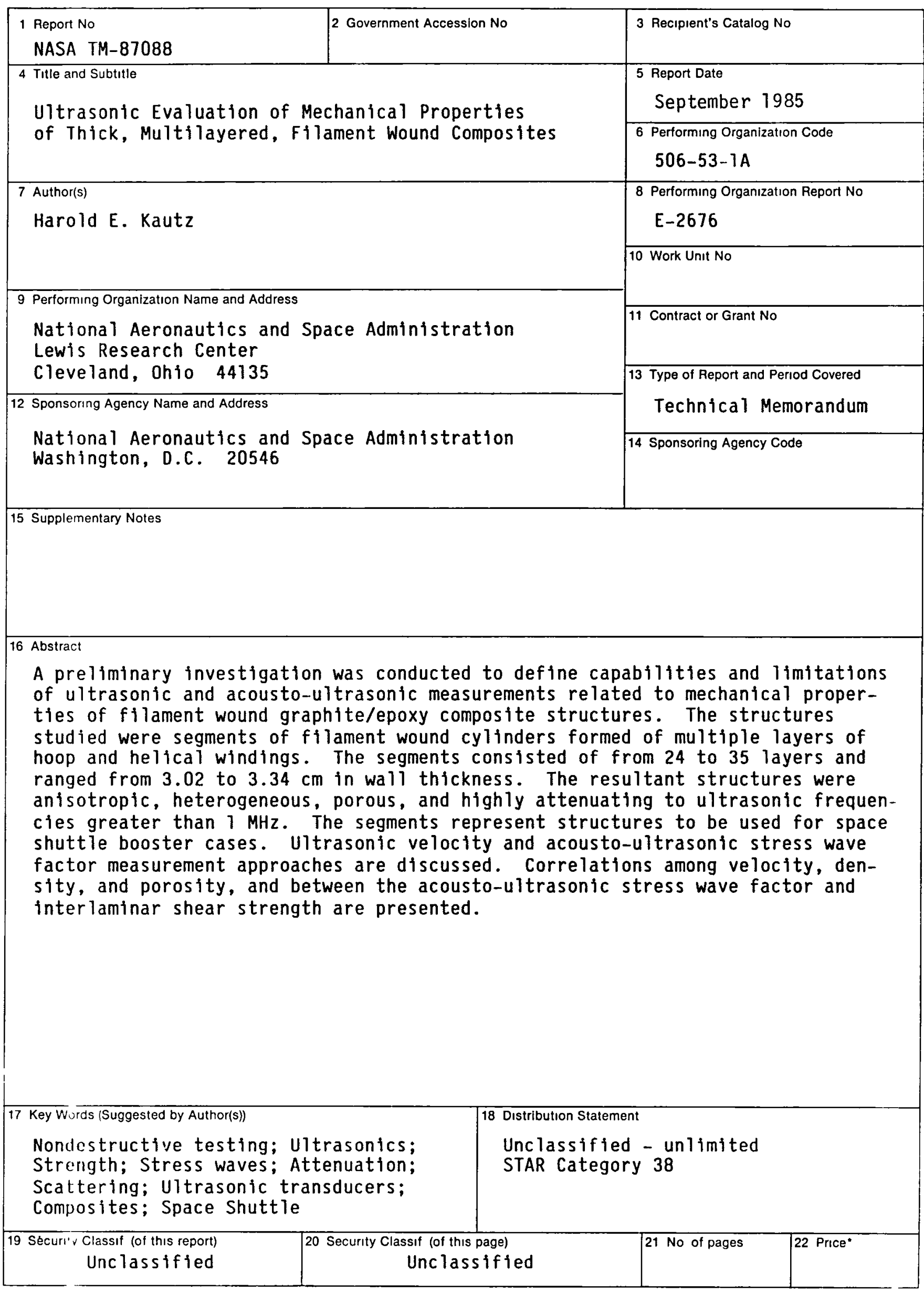

"For sale by the Natıonal Technıcal Information Service, Sprıngfıeld, Vırgınıa 22161 
End of Document 